\title{
Development of a simple groundwater model for use in climate models and evaluation with Gravity Recovery and Climate Experiment data
}

\author{
Guo-Yue Niu, ${ }^{1}$ Zong-Liang Yang, ${ }^{1}$ Robert E. Dickinson, ${ }^{2}$ Lindsey E. Gulden, ${ }^{1}$ \\ and Hua $\mathrm{Su}^{1}$ \\ Received 17 May 2006; revised 24 October 2006; accepted 26 December 2006; published 7 April 2007.
}

[1] Groundwater interacts with soil moisture through the exchanges of water between the unsaturated soil and its underlying aquifer under gravity and capillary forces. Despite its importance, groundwater is not explicitly represented in climate models. This paper developed a simple groundwater model (SIMGM) by representing recharge and discharge processes of the water storage in an unconfined aquifer, which is added as a single integration element below the soil of a land surface model. We evaluated the model against the Gravity Recovery and Climate Experiment (GRACE) terrestrial water storage change $(\Delta S)$ data. The modeled total water storage (including unsaturated soil water and groundwater) change agrees fairly well with GRACE estimates. The anomaly of the modeled groundwater storage explains most of the GRACE $\Delta S$ anomaly in most river basins where the water storage is not affected by snow water or frozen soil. For this reason, the anomaly of the modeled water table depth agrees well with that converted from the GRACE $\Delta S$ in most of the river basins. We also investigated the impacts of groundwater dynamics on soil moisture and evapotranspiration through the comparison of SIMGM to an additional model run using gravitational free drainage (FD) as the model's lower boundary condition. SIMGM produced much wetter soil profiles globally and up to $16 \%$ more annual evapotranspiration than FD, most obviously in arid-to-wet transition regions.

Citation: Niu, G.-Y., Z.-L. Yang, R. E. Dickinson, L. E. Gulden, and H. Su (2007), Development of a simple groundwater model for use in climate models and evaluation with Gravity Recovery and Climate Experiment data, J. Geophys. Res., 112, D07103, doi:10.1029/2006JD007522.

\section{Introduction}

[2] Groundwater storage constitutes about $30 \%$ of the global freshwater storage. This is a large percentage when compared with the amount of water stored in soil, wetlands, and permafrost, all of which constitute only $1 \%$ of the global freshwater. Groundwater interacts with soil, vegetation, and climate. Groundwater storage shows as large variations as that of soil water at monthly or longer timescales in Illinois [Rodell and Famiglietti, 2001]. The groundwater level also shows a strong diurnal cycle in aquifers where the water table depth is less than $2 \mathrm{~m}$ because of the water uptake by the roots of the aboveground plants [Fan et al., 2007]. Groundwater influences soil moisture and hence surface energy and water balances in regions where the water table is shallow [Gutowski et al., 2002; York et al., 2002; Liang et al., 2003; Chen and $H u, 2004 ;$ Yeh and Eltahir, 2005]. The rise and fall

\footnotetext{
${ }^{1}$ Department of Geological Sciences, The John A. and Katherine G. Jackson School of Geosciences, The University of Texas at Austin, Austin, Texas, USA.

${ }^{2}$ School of Earth and Atmospheric Sciences, Georgia Institute of Technology, Atlanta, Georgia, USA.

Copyright 2007 by the American Geophysical Union. 0148-0227/07/2006JD007522\$09.00
}

of the water table directly interacts with soil moisture in the vegetation root zone and thus acts as a source term for evapotranspiration. Through model studies, Gutowski et al. [2002] found that during relatively dry periods, up to $33 \%$ of monthly evapotranspiration was derived from groundwater-supported evapotranspiration. Simulation results [York et al., 2002] indicated that from 5\% (wet year) to $20 \%$ (dry year) of the evapotranspiration was drawn from groundwater in a catchment in northeastern Kansas. Therefore it is important to quantify water transfers from groundwater in determining land surface fluxes in climate models.

[3] Groundwater dynamics also control runoff generation, which can further affect the computation of soil moisture and evapotranspiration in a climate model. Observational data show that runoff is much more related to the water table depth than to precipitation at a monthly timescale in Illinois [Yeh and Eltahir, 2005]. Most climate models parameterize runoff processes as a sum of surface runoff (fast runoff) and subsurface runoff or base flow (slow runoff). The fast component is largely dominated by the fractional saturated area, i.e., the saturated fraction of a grid cell of climate models, where rainfall or snowmelt water immediately flows into local river systems and therefore does not support infiltration 
into the soil [Dunne and Black, 1970; Beven and Kirkby, 1979; Stieglitz et al., 1997]. The surface becomes saturated wherever the water table has reached the surface. The fractional saturated area is determined by the groundwater level (or the depth to water table) and the subgrid characteristics of the topography. The latter is described by statistics of the "topographic index" (or "wetness index," $\lambda=\ln (a / \tan \beta)$, where $a$ is the specific catchment area, i.e., the upstream area above a pixel that drains through the unit contour at the pixel, and $\tan \beta$ is the local surface topographic slope) computed from the high-resolution digital elevation model (DEM) [Quinn et al., 1995; Wolock and McCabe, 2000]. By fitting the discrete cumulative distribution function (CDF) of the topographic index using an exponential function, Niu et al. [2005] showed that the saturated fraction of a grid cell can be expressed as an exponential function of the water table depth.

[4] The slow component was formulated as drainage under gravity [Dickinson et al., 1993] or a downslope lateral drainage [Sellers et al., 1986] in earlier land surface models (LSMs). TOPMODEL formulated its base flow as an exponential function of the soil water storage deficit [Beven and Kirkby, 1979] or water table depth [Sivapalan et al., 1987]. The TOPMODEL-based runoff schemes for use in climate models also parameterized base flow as an exponential function of the catchment water storage deficit [Koster et al., 2000] or the water table depth [Famiglietti and Wood, 1994; Stieglitz et al., 1997; Chen and Kumar, 2001; Niu and Yang, 2003; Niu et al., 2005]. The exponential relationship between runoff (surface runoff and base flow) and the water table depth was demonstrated by observations [Figure 1b of Yeh and Eltahir, 2005]. However, when deriving the water table depth, these TOPMODELbased runoff schemes assume that the water head throughout the soil column is in equilibrium with that at water table under the steady state assumption, resulting in unrealistically shallow water tables [Koster et al., 2000; Chen and Kumar, 2001; Niu and Yang, 2003; Niu et al., 2005]. The steady state assumption is often unrealistic, especially during precipitation events. Additionally, these schemes, like most other LSMs, do not explicitly represent the water storage in the aquifer. When the soil is drying because of evapotranspiration, the soil can draw water through capillary suction from its underlying aquifer (or saturated layers), which has a longer memory of the past precipitation events than the soil. LSMs implicitly include such a process when the water table is shallow enough to be within the model soil layers. However, when the water table is below the model bottom, LSMs neglect this upward water flow through capillary forces while taking into consideration gravitational free drainage at the model bottom, resulting in unrealistically dry deep soil.

[5] The need for a groundwater component in LSMs has received increasing attention in the past few years. As a result, a number of researchers have incorporated a groundwater component into LSMs [Gutowski et al., 2002; York et al., 2002; Gedney and Cox, 2003; Liang et al., 2003; Maxwell and Miller, 2005; Yeh and Eltahir, 2005; Fan et al., 2007]. These models for use in climate studies can be divided in two categories: three-dimensional models [Gutowski et al., 2002; York et al., 2002; Fan et al.,
2007] and one-dimensional models [Gedney and Cox, 2003; Liang et al., 2003; Maxwell and Miller, 2005; Yeh and Eltahir, 2005]. Because the horizontal transport of groundwater is more pronounced at a smaller scale, threedimensional models are more applicable to regional climate and water resource studies, while one-dimensional models are more appropriate for global climate-groundwater interaction studies. Gedney and Cox [2003] added an unconfined aquifer below their LSM's soil column but assumed that the aquifer is in equilibrium with the lowest soil layer when the water table falls below the lowest soil layer. Other researchers [Liang et al., 2003; Yeh and Eltahir, 2005; Maxwell and Miller, 2005] have proposed more realistic solutions to solve the continuum of soil and relatively shallow aquifers but at the expense of adding more integration elements, i.e., 100 nodes, 50 layers, and 10 layers, respectively, in the above-referenced studies. Even with these additional layers, the models are only applicable for relatively shallow aquifers $(<5 \mathrm{~m})$ because of the prescribed depth of the model. A groundwater model for use in climate models should take into consideration not only shallow aquifers in wet regions but also deep aquifers in arid regions. We develop a simple groundwater model (SIMGM) for use in global climate models (GCMs) by adding only a single integration element, i.e., an underlying unconfined aquifer, to an LSM's soil column. Because SIMGM uses the water table as its lower boundary, the total model depth extends to the water table and varies in time and space with the water table. We evaluate the model's capability of simulating the variability of the total water storage and the water table depth using the Gravity Recovery and Climate Experiment (GRACE) estimates of terrestrial water storage change at a global scale.

\section{Model}

[6] In this study, we used a modified version of the National Center for Atmospheric Research (NCAR) Community Land Model version 2.0 (CLM2.0), in which a simple TOPMODEL-based runoff scheme [Niu et al., 2005] and a modified frozen soil scheme [Niu and Yang, 2006a] were implemented in the standard CLM2.0 [Bonan et al., 2002]. CLM2.0 computes soil temperature and soil water content in 10 soil layers to a depth of $3.43 \mathrm{~m}$. A detailed description of the model water and energy transfer processes within the soil and the vegetation canopy can be found in Oleson et al. [2004]. The modified frozen soil scheme introduced supercooled soil water by implementing a freezing-point depression equation and relaxed the dependence of the hydraulic properties on soil ice content by incorporating a concept of a fractional impermeable area, which enhanced the permeability of frozen ground [Niu and Yang, 2006a].

\subsection{A Simple TOPMODEL-Based Runoff Scheme}

[7] The simple TOPMODEL-based runoff model used here parameterizes both its surface runoff and base flow (groundwater discharge) as exponential functions of the water table depth. It defines the saturated hydraulic conductivity, $K_{\text {sat }}$, as a function of soil texture (as most other LSMs do). This definition is different from that of 


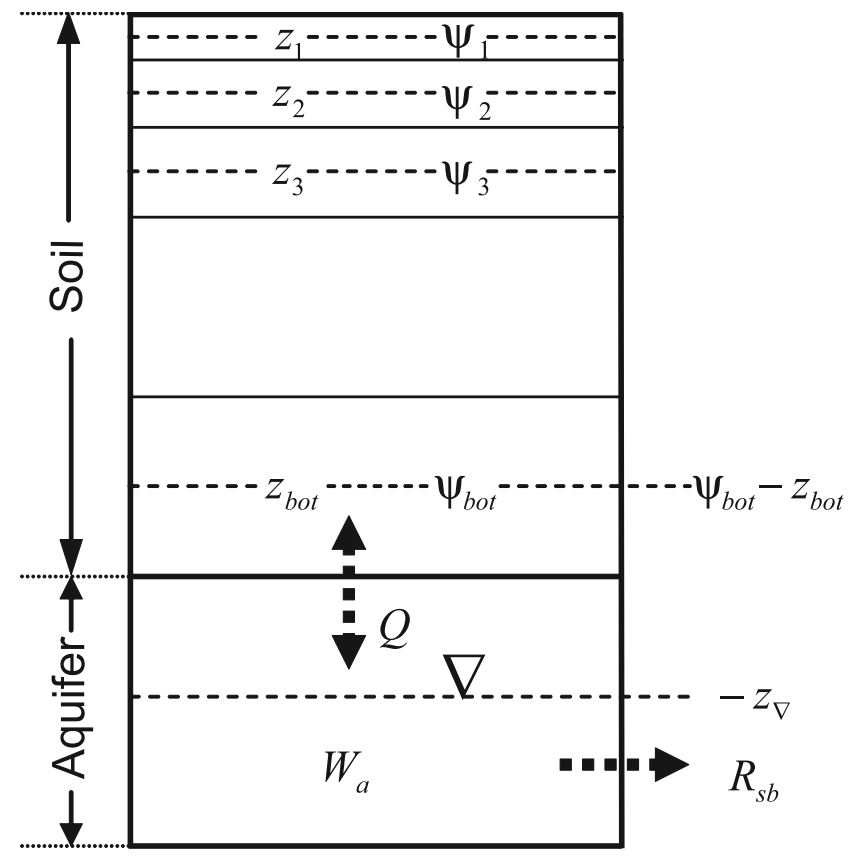

Figure 1. Schematic diagram of the soil layers and an unconfined aquifer. The depth to water table is represented by $z_{\nabla}$. The recharge rate $Q$ is proportional to the difference between the water head at the bottom layer $\left(\psi_{\text {bot }}-z_{\text {bot }}\right)$ and that at the water table $\left(-z_{\nabla}\right)$. The water head at the water table approximates $-z_{\nabla}$ for the reason that the capillary pressure head $\left(\psi_{\text {sat }}\right)$ is negligible compared to the elevation head $-z_{\nabla}$.

TOPMODEL, which assumes $K_{\text {sat }}$ decays from a very large value at the soil surface. Surface runoff takes the form of:

$$
R_{\mathrm{s}}=F_{\mathrm{sat}} Q_{\mathrm{wat}}+\left(1-F_{\mathrm{sat}}\right) \max \left(0,\left(Q_{\mathrm{wat}}-I_{\mathrm{max}}\right)\right)
$$

where $Q_{\text {wat }}$ is the water incident on the soil surface (sum of rainfall, dewfall, and snowmelt), and $I_{\max }$ is the soil infiltration capacity dependent on soil texture and moisture. The saturated fraction $F_{\text {sat }}$ is parameterized as:

$$
F_{\text {sat }}=\left(1-F_{\text {frz }}\right) F_{\text {max }} \mathrm{e}^{-0.5 f z_{\nabla}}+F_{\text {frz }}
$$

where $F_{\max }$, the potential or maximum saturated fraction of a GCM grid cell, is defined as the cumulative distribution function of the topographic index when the grid-cell-mean water table depth is zero. Determined by the subgrid topography of a GCM grid cell (for instance, at a $1^{\circ}$ resolution), $F_{\max }$ is the fraction of the accumulative area of highresolution subgrid cells (for instance, at a $1-\mathrm{km}$ resolution) that have a topographic index being equal to or larger than the average topographic index of the GCM grid cell (see Niu et al. [2005] for detail). $F_{\text {frz }}$ is the fractional impermeable area as a function of soil ice content of the surface layer [Niu and Yang, 2006a]. The decay factor $f$ can be determined through sensitivity analysis or calibration against hydrograph recession curve.

[8] Subsurface runoff (or groundwater discharge) is parameterized as:

$$
R_{\mathrm{sb}}=R_{\mathrm{sb}, \max } \mathrm{e}^{-f z_{\nabla}}
$$

where $R_{\mathrm{sb} \text {,max }}$ is the maximum subsurface runoff when the grid-cell-averaged water table depth is zero. $R_{\text {sb,max }}$ corresponds to a complex product of parameters used in TOPMODEL [Sivapalan et al., 1987]. $R_{\mathrm{sb}, \max }=\alpha K_{\mathrm{sat}}(0) \mathrm{e}^{-\lambda} / f$, where $\alpha$ is an anisotropic factor used to convert the surface value of saturated hydraulic conductivity in the vertical direction, i.e., $K_{\mathrm{sat}}(0)$, to the value in the lateral direction [Kumar, 2004], $\lambda$ is the grid-cell-mean topographic index, and $f$ is the decay factor. Because of the lack of a global highresolution DEM (e.g., $30 \times 30 \mathrm{~m}$ ) to derive accurate topographic indexes and sufficient data to derive grid-cellspecific hydraulic parameters for unconfined aquifers, we treat this complex product as a calibration parameter for global simulations.

[9] The standard CLM2.0 lacks a groundwater component. It uses the gravitational drainage as the lower boundary condition for its soil hydrology as many other land surface models do:

$$
q=k_{\text {bot }}
$$

where $q$ is the water flux at the model bottom and $k_{\text {bot }}$ is the hydraulic conductivity at the bottom soil layer (i.e., the 10th soil layer). Equation (4) also serves as a source of subsurface runoff in the model. When we applied the simple TOPMODEL-based runoff model to the standard CLM2.0 [Niu et al., 2005], we assumed a zero-flux lower boundary condition, i.e., $q=0$. Because the model lacks a groundwater component, the TOPMODEL-produced subsurface runoff (equation (3)) is then unrealistically extracted from the deep soil water rather than groundwater. To represent groundwater recharge and discharge processes in a more physically realistic way, we describe a dynamic coupling between the bottom soil layer and an unconfined aquifer. The groundwater recharge under gravity and capillary forces also serves as the lower-boundary condition for the soil hydrology.

\subsection{A Simple Groundwater Model (SIMGM)}

[10] An aquifer is often defined as the geological structures constituting of soil, gravel, and/or permeable rock where groundwater resides. In this paper, we define the "aquifer" as the part below the model soil column (Figure 1). The temporal variation of the water stored in an unconfined aquifer, $W_{\mathrm{a}}(\mathrm{mm})$, is expressed as:

$$
\frac{\mathrm{d} W_{\mathrm{a}}}{\mathrm{d} t}=Q-R_{\mathrm{sb}}
$$

where $Q$ is the recharge ( $\mathrm{mm} \mathrm{s}^{-1}$ ) to the aquifer and $R_{\mathrm{sb}}$ is the discharge $\left(\mathrm{mm} \mathrm{s}^{-1}\right)$ (base flow or subsurface runoff) from the aquifer. The recharge rate $Q$ is then formulated by Darcy's law and is positive when water enters the aquifer:

$$
Q=-K_{\mathrm{a}} \frac{-z_{\nabla}-\left(\psi_{\mathrm{bot}}-z_{\mathrm{bot}}\right)}{z_{\nabla}-z_{\mathrm{bot}}}
$$

where $z_{\nabla}$ is the depth to the water table, $\psi_{\text {bot }}$ is the matric potential of the bottom layer, and $z_{\text {bot }}(=2.89 \mathrm{~m})$ is the node depth of the bottom layer (Figure 1). Equation (6) accounts for not only gravitational drainage $\left(K_{\mathrm{a}}\right)$ but also 
the upward water flux $\left(K_{\mathrm{a}} \frac{\psi_{\text {bot }}}{z_{\nabla}-z_{\text {bot }}}\right)$ driven by capillary forces. The latter becomes significant when the soil is dry (a large negative value of $\left.\psi_{\text {bot }}\right)$ and the water table is not very deep. It has traditionally been ignored by land surface models. $\psi_{\text {bot }}=\psi_{\text {sat,bot }}\left(\theta_{\text {liq,bot }} / \theta_{\text {sat,bot }}\right)^{-b}$ is the matric potential of the bottom layer, where $\theta_{\text {sat,bot }}$ and $\psi_{\text {sat,bot }}$ are the porosity and the saturated matric potential of the bottom layer, respectively, and $b$ is a parameter that depends on soil texture [Clapp and Hornberger, 1978]. Note that including only the liquid water in this equation accounts for the effect of frozen soil on groundwater level. Densely sampled hydraulic conductivity data are available for only a very few aquifers. We assume that the hydraulic conductivity below the model soil column decays exponentially with depth from the hydraulic conductivity of the bottom layer: $k_{\text {bot }} \mathrm{e}^{-f\left(z-z_{\text {bot }}\right)}$, where $f$ is a decay factor, the same as that in the simple TOPMODEL described above, while the hydraulic conductivity within the soil column is still determined by soil texture [Gedney and Cox, 2003]. Thus the hydraulic conductivity of the aquifer $K_{\mathrm{a}}$ is:

$$
K_{\mathrm{a}}=\frac{\int_{z_{\mathrm{bot}}}^{z_{\nabla}} k_{\mathrm{bot}} \mathrm{e}^{-f\left(z-z_{\mathrm{bot}}\right)} \mathrm{d} z}{z_{\nabla}-z_{\mathrm{bot}}}=\frac{k_{\mathrm{bot}}\left(1-\mathrm{e}^{-f\left(z_{\nabla}-z_{\mathrm{bot}}\right)}\right)}{f\left(z_{\nabla}-z_{\mathrm{bot}}\right)}
$$

[11] The water table depth $z_{\nabla}$ is then converted from the aquifer water storage scaled by the specific yield $S_{\mathrm{y}}$, i.e., the fraction of water volume that can be drained by gravity in an unconfined aquifer. While $S_{\mathrm{y}}$ on average ranges from 0.02 for clay, 0.07 for sandy clay, 0.18 for silt to 0.27 for coarse sand [Fetter, 1988], we use a constant $S_{\mathrm{y}}=0.2$ in the global simulations because of the dearth of specific yield data for global aquifers.

[12] The volumetric soil moisture of the bottom layer $\theta_{\text {bot }}$ solved from Richards' equation with a zero-flux lowerboundary condition is then updated with the recharge rate:

$$
\rho_{\mathrm{w}} \Delta z_{\mathrm{bot}} \frac{\mathrm{d} \theta_{\mathrm{bot}}}{\mathrm{d} t}=-Q
$$

where $\rho_{\mathrm{w}}$ and $\Delta z_{\text {bot }}$ are liquid water density and the thickness of the bottom layer, respectively.

[13] The above descriptions are only applicable to the case when the groundwater level is lower than the depth of the bottom layer $(3.43 \mathrm{~m})$. When the water table is within the soil column, there is no exchange of water between the soil column and its underlying aquifer as shown in Figure 1. Equation (5) remains unchanged, while equation (6) for the recharge rate is modified as:

$$
Q_{i}=-K_{i, \nabla} \frac{\left(\psi_{\mathrm{sat}}-z_{\nabla}\right)-\left(\psi_{i}-z_{i}\right)}{z_{\nabla}-z_{i}}
$$

where $\psi_{i}$ and $z_{i}$ are the matric potential and the node depth of the $i$ th layer that is right above the layer where the water table resides, respectively. $K_{i, \nabla}$ is the hydraulic conductivity between layer $i$ and the water table. Note that the water head at the water table is a sum of capillary head and elevation head $\left(\psi_{\text {sat }}-z_{\nabla}\right)$ instead of only the elevation head $\left(-z_{\nabla}\right)$ in equation (6) because the capillary head $\psi_{\text {sat }}$ is comparable to the elevation head $-z_{\nabla}$ when the water table is near the surface. In such a case, the specific yield is substituted with the volume of air pores (the pore space not filled with water) within the soil to convert $W_{\mathrm{a}}$ to the water table depth. To conserve mass, the groundwater discharge (base flow) is extracted from the saturated soil layers (the part of aquifer above the bottom of the model soil column) rather than from the "aquifer" (the part of aquifer below the bottom of the model soil column), and the partitioning of the discharge to different saturated soil layers is proportional to the layerthickness-weighted hydraulic conductivity as described by Niu et al. [2005].

[14] To obtain the water table depth, we assume $W_{\mathrm{a}}=$ $10.0 \mathrm{~m}$ when $z_{\nabla}=3.43 \mathrm{~m}$, i.e., the depth of model soil column. Thus $W_{\mathrm{a}}=0.0 \mathrm{~m}$ is equivalent to $z_{\nabla}=\left(10.0 / S_{\mathrm{y}}+\right.$ $3.43)=53.43 \mathrm{~m}$. $W_{\mathrm{a}}$ can be a negative value when the water table falls down below $53.43 \mathrm{~m}$. This approach allows the model to simulate the water table depth using the variations of $W_{\mathrm{a}}$ instead of the absolute value of $W_{\mathrm{a}}$. To model the absolute value of $W_{\mathrm{a}}$, one must have a global data set of the water stored in global aquifers as the model's initial condition. Such a data set does not yet exist.

[15] Adding a single-layer aquifer to the bottom of the soil column differs from adding a soil layer or extending the model depth in four aspects.

[16] (1) SIMGM explicitly solves the water table depth and uses the water table depth as the lower boundary condition. It thus does not need to have a prescribed total model depth as other groundwater models do.

[17] (2) The aquifer in SIMGM has hydraulic properties that are different from a soil layer (specific yield and the exponentially decaying hydraulic conductivity).

[18] (3) The capillary pressure head in the aquifer is negligible.

[19] (4) Unlike a soil layer, there is no gravitational drainage at the bottom of the aquifer. SIMGM highly parameterizes the lateral transport of groundwater between grid cells and to river systems through the TOPMODEL base flow formulation, i.e., equation (3). For this reason, SIMGM does not explicitly account for groundwater flow from cell to cell and exchange with streams as does the model described in the work of Fan et al. [2007].

\section{Evaluate SIMGM With Global Data Sets}

[20] Because SIMGM is developed for global climate models, it is important to test its performance using global data sets. We used the Global Land Data Assimilation System (GLDAS) $1^{\circ} \times 1^{\circ} 3$-hourly, near-surface meteorological data for the years 2002-2004 [Rodell et al., 2004a] to drive the model. These forcing data are observation-based fields including precipitation, air temperature, air pressure, specific humidity, short-wave and long-wave radiation, and wind speed. Although the GLDAS forcing used in this study is not sufficiently long to produce a runoff climatology, it covers the same period during which the terrestrial water storage change measured by GRACE satellites is available.

[21] The vegetation and soil parameters at $1^{\circ} \times 1^{\circ}$ were interpolated from the high-resolution raw data of the NCAR standard CLM2.0. The maximum saturated fraction $F_{\max }$ is derived from the subgrid distributions of the $1 \times 1 \mathrm{~km}$ 
HYDRO1K global wetness index (or topographic index) data set (see Niu et al. [2005] for detail). The runoff decay factor is determined as $f=1.25 \mathrm{~m}^{-1}$ through sensitivity experiments against the Global Runoff Data Centre (GRDC) runoff. The maximum base flow parameter $R_{\mathrm{sb}, \max }=4.5 \times$ $10^{-4} \mathrm{~mm} \mathrm{~s}^{-1}$ is obtained through sensitivity experiments to match the observed water table depths of 16 wells in Illinois. $R_{\mathrm{sb}, \max }$ affects the magnitude of the groundwater storage and the water table depth by changing groundwater discharge. Through sensitivity studies, Niu et al. [2005] found that the increase in $R_{\mathrm{sb} \text {, max }}$ from $0.5 \times 10^{-4}$ to $7.0 \times$ $10^{-4} \mathrm{~mm} \mathrm{~s}^{-1}$ has negligible impacts on the magnitude of the total runoff, although it reduces the ratio of the surface runoff to the total runoff from 0.4 to 0.15 . When transferring the calibrated value $\left(4.5 \times 10^{-4} \mathrm{~mm} \mathrm{~s}^{-1}\right)$ in Illinois to global continents, we are aware that it can induce errors in the mean state of the water table depth in other regions but negligible errors in the seasonal variations of the water table depth and the total runoff.

\subsection{Initialize the Water Table Depth With the Equilibrium Water Table Depth}

[22] To reduce the uncertainties induced by initial conditions, we first ran the model for 3 years from 2002 to 2004 and saved the model prognostic variables at the end of the run. We then used the saved prognostic variables as the initial conditions for another 3-year run. Following the definition of equilibrium described by Yang et al. [1995], the model needs to spin-up for at least 250 years to reach an equilibrium water table depth in arid regions (e.g., Sahara) and for only a few years in wet regions (e.g., Amazon), when the model is initialized with a water table depth of $4.43 \mathrm{~m}(1.0 \mathrm{~m}$ below the bottom of the modeled soil profile). We used the following efficient approach to obtaining the equilibrium water table depth.

[23] Assuming the recharge rate $Q=0$, i.e., the water head at the water table is in equilibrium with that of the bottom soil layer, we then derive the equilibrium water table depth $z_{\nabla, \text { eq }}$ from equation (6):

$$
z_{\nabla, \mathrm{eq}}=z_{\mathrm{bot}}-\psi_{\mathrm{sat}} s_{\mathrm{bot}}^{-b}
$$

where $s_{\text {bot }}$ is the degree of saturation of the bottom layer. For a sandy soil $\left(\psi_{\text {sat }}=-0.121 \mathrm{~m}\right.$, and $\left.b=4.05\right)$ at a saturation of $0.3, z_{\nabla, \mathrm{eq}}=18.75 \mathrm{~m}$.

[24] We span up the model equipped with equation (10) from 2002 to 2004 until the soil moisture at the bottom layer reaches its equilibrium. Using this method, we obtained $z_{\nabla \text {,eq }}$ because $z_{\nabla \text {,eq }}$ is only determined by the soil moisture of the bottom layer. This $z_{\nabla \text {,eq }}$ and the water storage converted from $z_{\nabla, \text { eq }}$ multiplied by the specific yield are used as initial conditions for further runs. SIMGM is then spun-up two times until the water table in wet regions reaches equilibrium.

\subsection{Evaluate SIMGM Against GRDC Runoff Product}

[25] The global runoff data set used in this study is the University of New Hampshire (UNH)-GRDC monthly runoff climatology. The UNH-GRDC data set provides monthly climatological runoff fields, which are runoff outputs from a water balance model that is driven by observed meteorological data and then corrected with the runoff fields that are disaggregated from the observed river discharges. Although a no-time-delay assumption is applied when the gauge-observed discharge is distributed uniformly over a catchment, the resulting runoff fields over a large river basin approximate the real runoff, especially in river basins that contain a sufficiently dense network of rain gauges. The UNH-GRDC data set preserves the accuracy of the observed discharge measurements and maintains the spatial and temporal distribution of the simulated runoff, thereby providing the "best estimate" of terrestrial runoff over large domains [Fekete et al., 2000].

[26] CLM2.0 with SIMGM reproduces the GRDC runoff climatology (Figure 2). The spatial distribution of the modeled runoff agrees well with that of the GRDC runoff. Both the modeled and observed data show higher runoff in wet regions with relatively shallow water tables, such as the Amazon, the Congo River basin, the eastern U.S., southern China, the Indian monsoon region, Europe, and west Siberia. Both show lower runoff in arid regions with deeper water tables, such as the Sahara Desert, the Middle East, northern China, the western U.S., and Australia. The modeled water table depth ranges from $2.0 \mathrm{~m}$ in wet regions to $30 \mathrm{~m}$ or deeper in arid regions. The modeled global-mean runoff $(0.70 \mathrm{~mm} /$ day $)$ is about $9 \%$ higher than GRDC estimates $(0.64 \mathrm{~mm} /$ day $)$. This discrepancy may be either explained by the uncertainties in precipitation or radiation estimates or by the accelerated hydrological cycle due to global warming [Gedney et al., 2006] (GRDC runoff is estimated through longer past discharge records, while the modeled runoff is during 2002-2004). The spatial distribution of the modeled water table depth is consistent with both the model simulated and the GRDC runoff fields. Because runoff is mainly controlled by water table depth in the model, evaluation of runoff can be viewed as an indirect evaluation of the model's ability to simulate global spatial distribution of the water table depth.

[27] The regional averages for different climate zones are shown in Figure 3. The model performs very well in simulating the GRDC runoff in most regions except for the mountainous western U.S., where the precipitation is underestimated by a factor of 2 [Pan et al., 2003; Adam et al., 2006], and the eastern U.S., where the runoff seasonality is sensitive to the partition of precipitation into snowfall and rainfall, the realistic representation of which has proved challenging to achieve within the land-surface modeling framework. Modeled surface runoff is mostly generated when liquid water falls on the fractional saturated area and provides only a small fraction of the total runoff (about 20\%). Most of the modeled runoff (about 80\%) is from the groundwater discharge (base flow).

[28] Runoff varies mainly with the water table depth in the simple TOPMODEL framework used here and described in section 2.1. Consistent with the findings in $\mathrm{Niu}$ et al. [2005], the agreement between the modeled runoff and the GRDC runoff suggests that the mechanism to generate runoff, i.e., the exponential dependence of runoff on the water table depth, is applicable in most regions in globalscale models. However, this does not mean that the magnitude and the seasonality of the modeled water table depth are necessarily realistic or comparable to the observed water table depth from wells. The observed water table depth may 

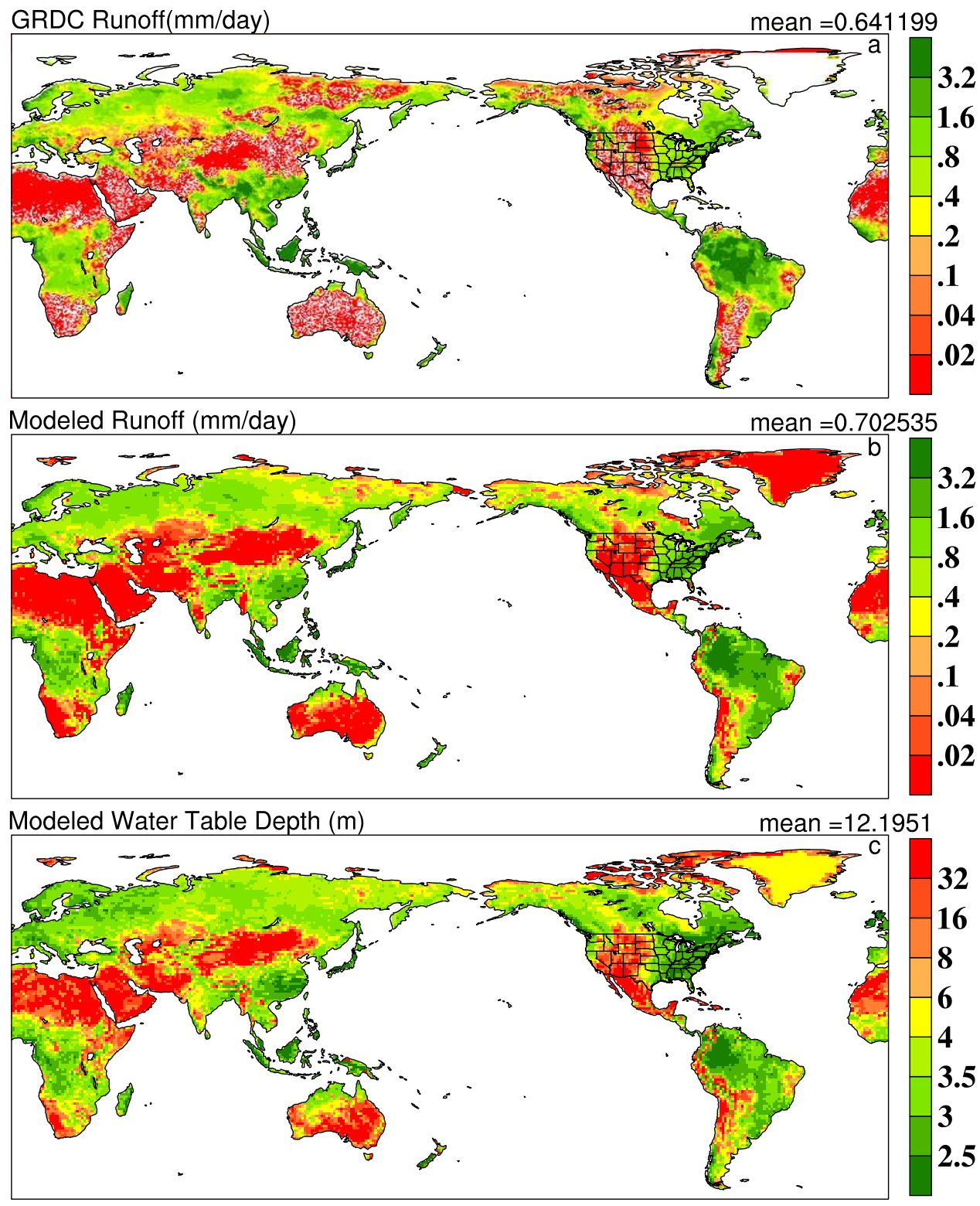

Figure 2. (a) GRDC runoff climatology, (b) the modeled 2002-2004 averaged runoff, and (c) the modeled 2002-2004 averaged water table depth.

show a great spatial variability because of heterogeneity of the underground geological structures and groundwater pumping by humans. Therefore even if we have a global data set of the water table depth, we cannot ensure a comparison of the modeled water table depth to the observed data. However, data derived from NASA's GRACE satellites provide us with an unprecedented opportunity to observe on a global scale terrestrial water storage change, which reflects groundwater dynamics. We will show that the modeled groundwater storage change is consistent with GRACE retrievals of the terrestrial water storage change in the next subsection.

\subsection{Evaluate the Modeled Water Storage Variations With GRACE}

[29] Terrestrial water storage (TWS) includes water stored as soil moisture, snow, and ice, groundwater, lakes and rivers, and the water contained in biomass. The GRACE satellites, launched 17 March 2002, are measuring Earth's gravity field with enough precision to infer TWS change $(\Delta S)$ over large regions [Wahr et al., 2004; Tapley et al., $2004]$. These time-variable gravity observations can be used to infer mass redistribution (e.g., terrestrial water storage change) [e.g., Wahr et al., 2004; Tapley et al., 2004; Chen et al., 2005] on Earth's surface at an accuracy of approximately $1.5 \mathrm{~cm}$ of equivalent water thickness change at about $1000 \mathrm{~km}$ spatial scale [Wahr et al., 2004]. Rodell et al. [2004b] demonstrated that the GRACE-derived $\Delta S$ change is useful to estimate basin-scale evapotranspiration $(E)$ when combined with observed precipitation and river discharge data. GRACE $\Delta S$ change also compares fairly well with the water storage (including canopy intercepted water, soil water, and snow) variations modeled by LSMs [Chen et al., 2005; Niu and Yang, 2006b]. 

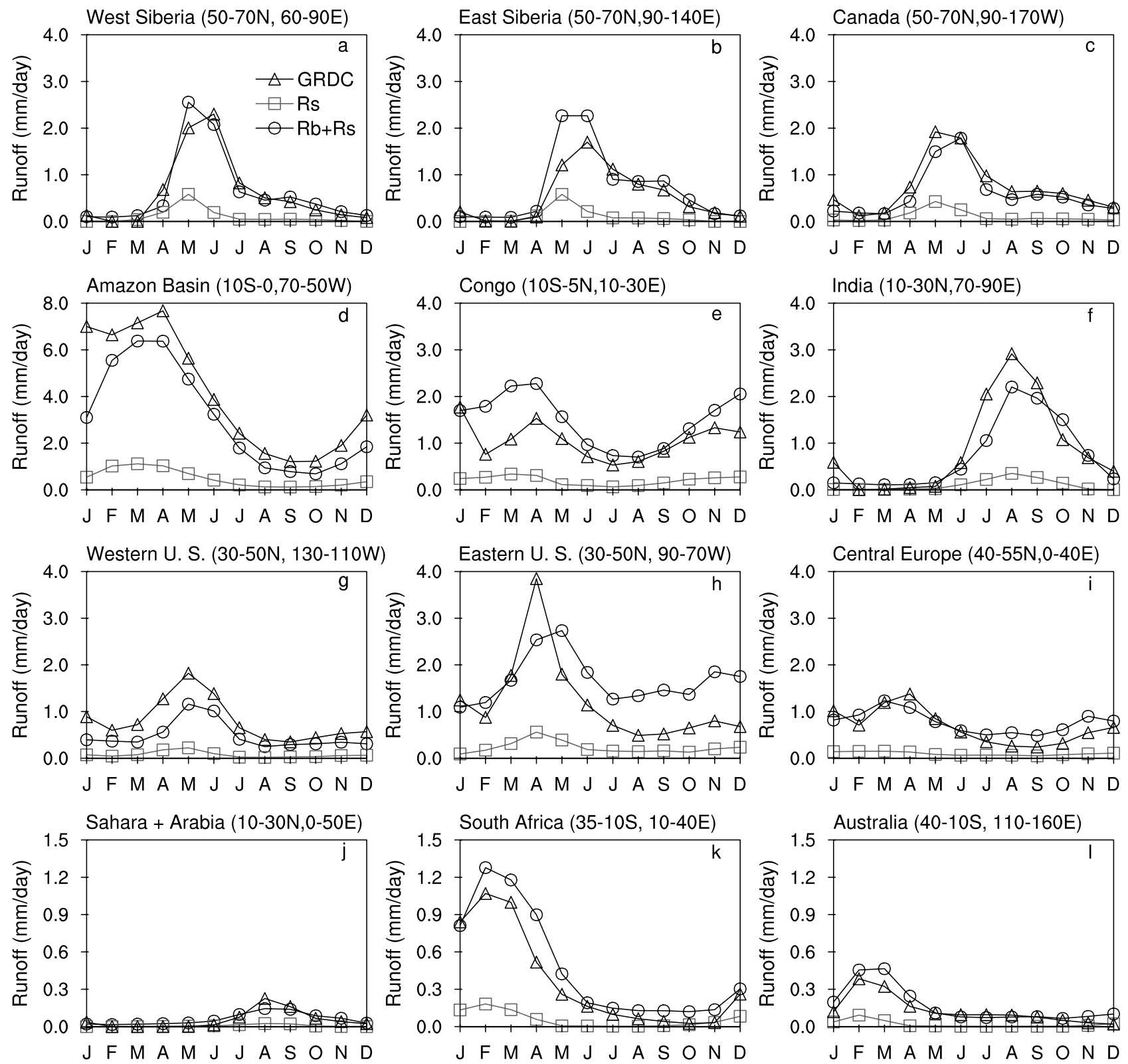

Figure 3. Modeled 3-year mean monthly runoff $(\mathrm{Rb}+\mathrm{Rs})$ and surface runoff $(\mathrm{Rs})$ in comparison with the GRDC climatological monthly runoff in $(\mathrm{a}-\mathrm{c})$ arctic and boreal latitudes, $(\mathrm{d}-\mathrm{f})$ tropical latitudes, $(\mathrm{g}-\mathrm{i})$, midlatitudes, and $(\mathrm{j}-\mathrm{l})$ arid latitudes.

[30] We used two GRACE data sets that are derived using different filtering algorithms [Seo and Wilson, 2005; Chen et al., 2005] to infer the uncertainties in GRACE estimates. These two data sets contain monthly data of the water storage change starting from August 2002 to December 2004. We selected the monthly averaged modeled data of the same month as those of GRACE to compute the anomaly of the water storage.

[31] The modeled total water storage anomaly (including groundwater and unsaturated soil water) compares fairly well with the two GRACE data sets in terms of interannual and interbasin variability for all the selected river basins (Figure 4). The modeled groundwater storage variations explain most of the total water storage variations in all these river basins (Figure 4). In the Mississippi river basin (Figure 4), the groundwater storage decreases in winter because of soil water freezing (decreasing the mass of liquid water), while the GRACE-measured water storage change increases mainly because of snow accumulated on the ground. Because the modeled groundwater storage only reflects liquid water storage, it is not expected to be consistent with the GRACE estimates in cold regions where the water table is affected by frozen soil or snow water.

[32] To evaluate the variability of the modeled water table depth, we converted the GRACE water storage $\left(\Delta S_{\text {GRACE }}\right)$ variations by the specific yield into the variations of water table depth as follows:

$$
z_{\nabla, \mathrm{GRACE}}=-\Delta S_{\mathrm{GRACE}} / S_{\mathrm{y}}
$$



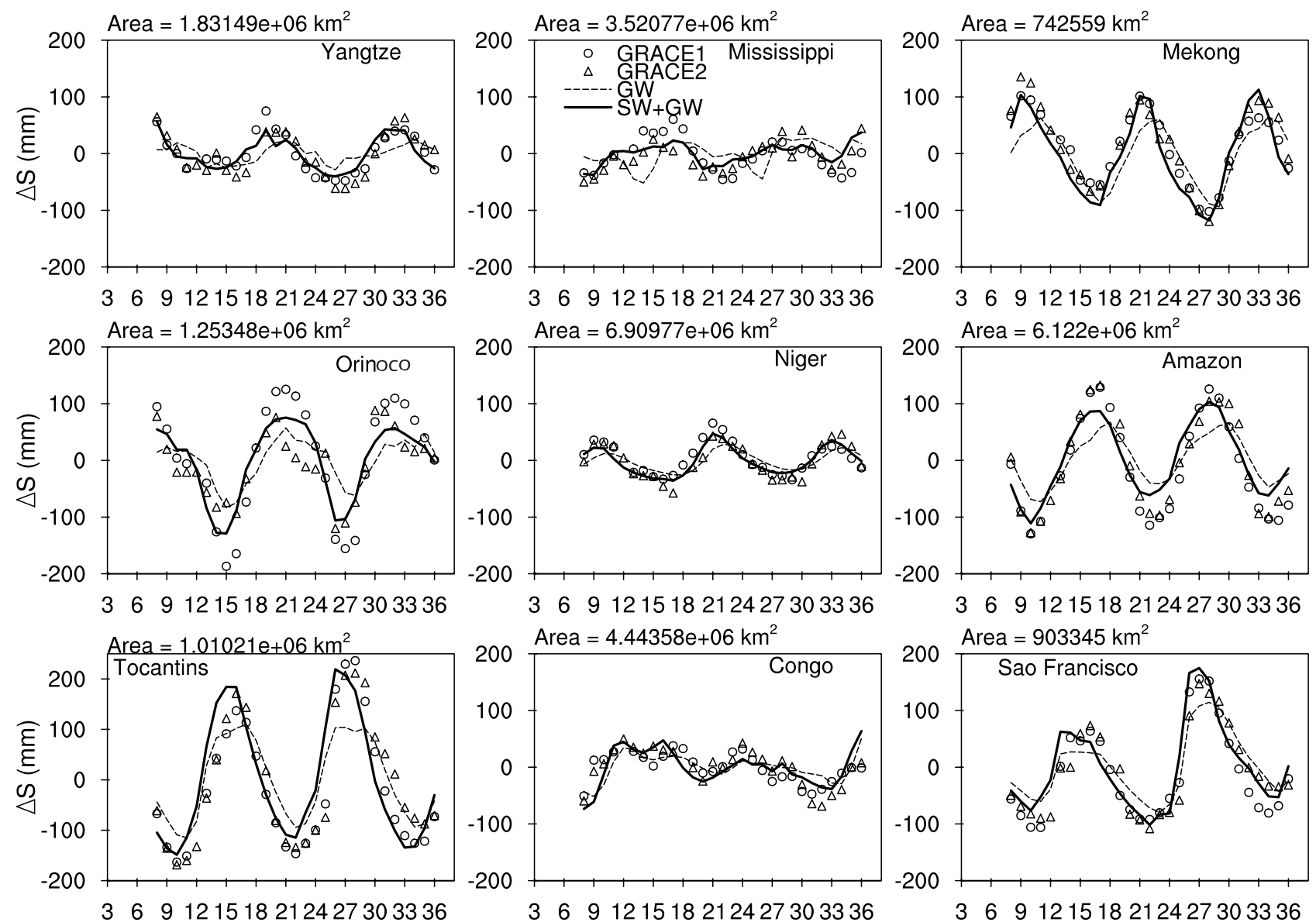

3699121518212427303336

369121518212427303336
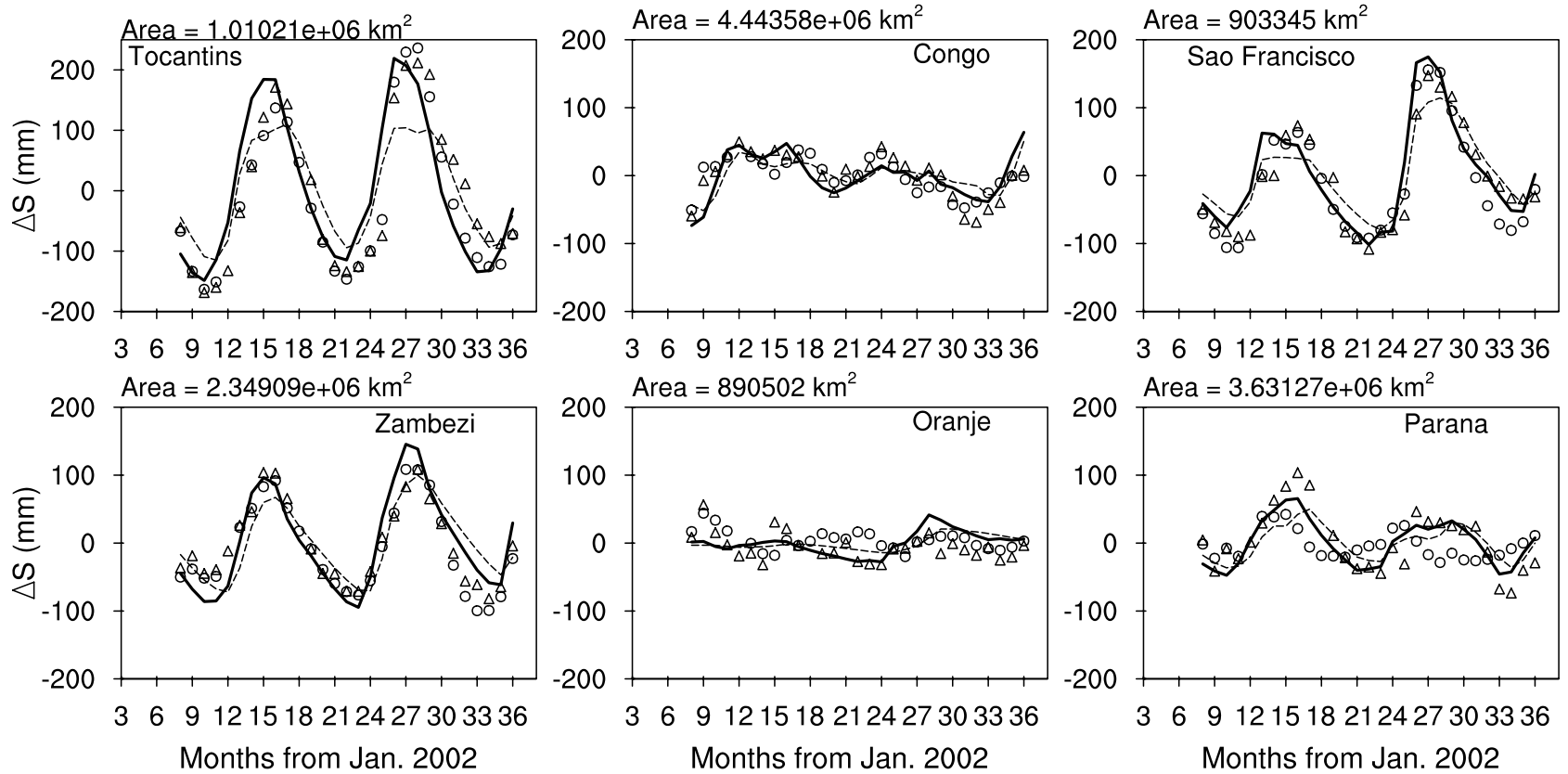

369121518212427303336

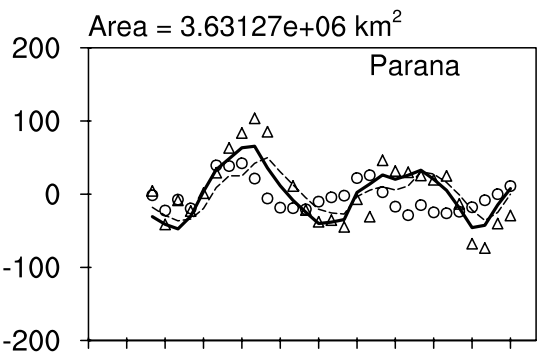

3699121518212427303336

Months from Jan. 2002

Figure 4. Modeled river-basin averaged anomalies of the total water storage (unsaturated soil water + groundwater: SW + GW, except for Mississippi, where snow water is also included) and groundwater storage $(\mathrm{GW})$ in comparison with GRACE water storage anomaly.

where $S_{\mathrm{y}}=0.2$ globally, the same value as used in SIMGM. The anomalies of the modeled water table depth agree well with those of $z_{\nabla, \mathrm{GRACE}}$ with regard to the interannual and interbasin variability in most of the river basins, except for the Orinoco river basin. The Orinoco river basin, which is located north of equator, is adjacent to the Amazon River basin, which is in south of equator. The seasonality of rainfall in these two river basins is out of phase. Therefore the GRACE water storage anomaly in Orinoco is greatly attenuated by that in the Amazon when a smoothing technique is applied to filter the GRACE noise. The attenuation is more pronounced in GRACE2, which uses a Gaussian averaging function with a $1000-\mathrm{km}$ radius, especially during months $21-24$ (using a $600-\mathrm{km}$ radius data partly solves this problem). The corruption of the Orinoco signal by the adjacent Amazon reflects an extreme case in the uncertainties of the GRACE estimates due to smoothing. The extreme uncertainty in this region must be taken into account when interpreting discrepancies between model and GRACE in this region.

[33] The amplitude of the modeled water storage anomaly is smaller than that of the GRACE derived, mostly obvious in the Amazon River basin (Figure 4). Because both the model and GRACE use the same specific yield to convert water storage to water table depth, the amplitude of the modeled water table-depth anomaly should be smaller than that of $z_{\nabla, \text { GRACE }}$ anomaly. However, when the water table is 

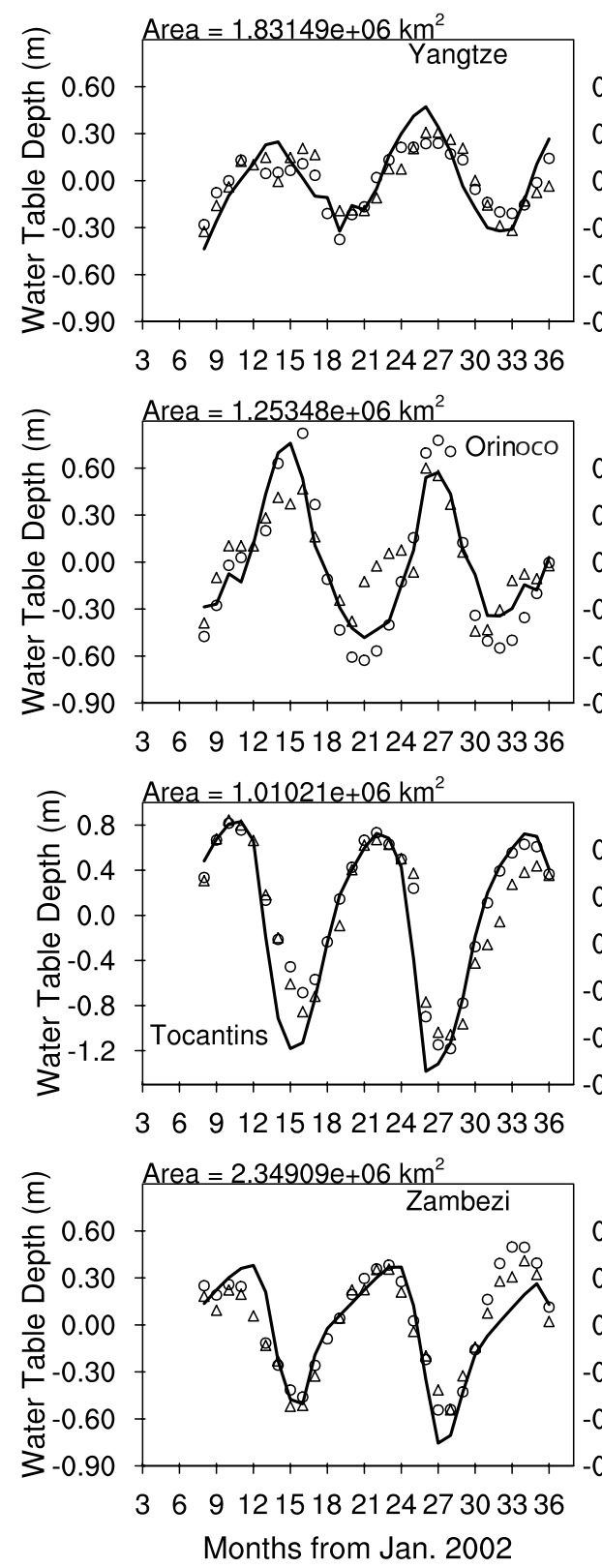
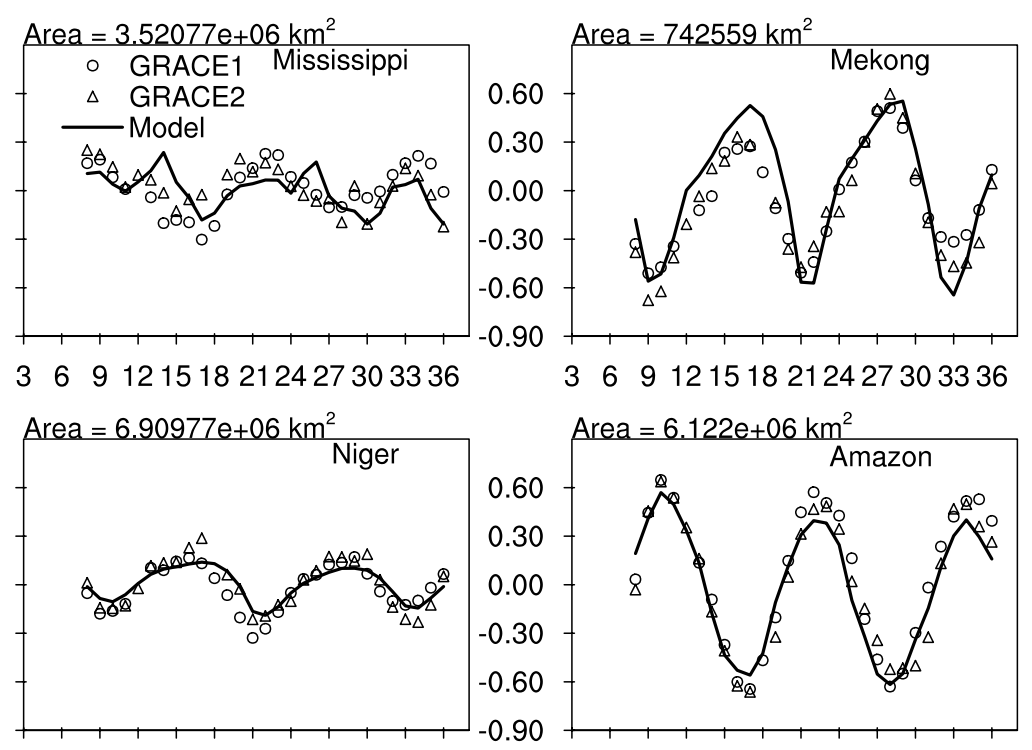

$36 \quad 9121518212427303336$

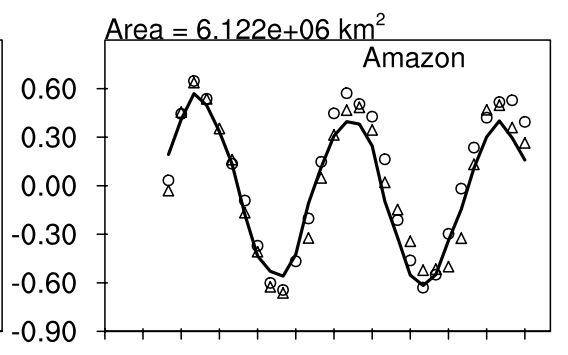

369121518212427303336
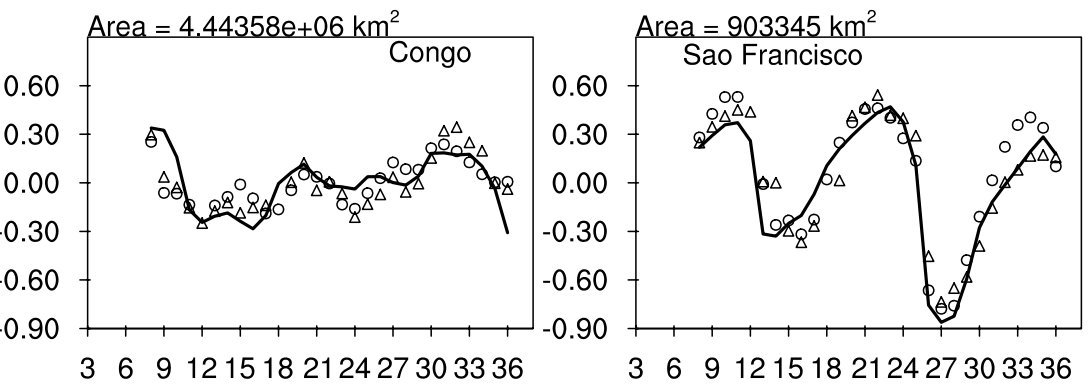

3699121518212427303336
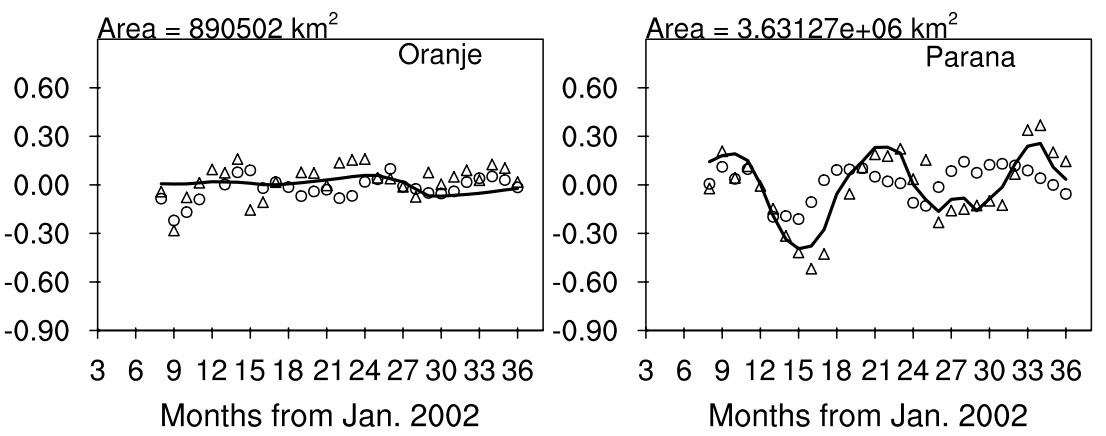

Figure 5. Same as Figure 4, but for the water table depth.

within the soil column, the water storage is converted by the air pore space instead of the specific yield in the model. Because the air pore space is usually less than specific yield, the amplitude of the modeled water table depth anomaly is thus amplified to approximate $z_{\nabla, \text { GRACE }}$ (Figure 5). Although the comparison is not strict, the agreement between the anomalies of modeled water table depth and $z_{\nabla, \mathrm{GRACE}}$ indicates that GRACE measured water storage change can approximate the change in water table.

[34] Model simulations also indicate that the variability of precipitation minus evapotranspiration $(P-E)$ controls the variability of the model groundwater recharge, discharge, and hence groundwater storage and the water table depth (Figure 6). The modeled groundwater recharge increases as $P-E$ increases during wet seasons $(P-E>0)$ and decreases as $P-E$ decreases during dry seasons $(P-E<0)$. The modeled groundwater recharge rate becomes negative soon after $P-E$ becomes negative. Therefore the negative recharge rates under capillary forces happen when $P-E<0$ and are mainly driven by $E$. In response to the modeled groundwater recharge, the modeled groundwater discharge also increases during the wet seasons and decreases in the dry seasons but has a smaller magnitude than the modeled groundwater recharge. The groundwater discharge is solely determined by the water table depth in our runoff scheme and matches very well the GRDC runoff (Figure 2) because most of the modeled runoff is from groundwater discharge. The interbasin and interannual variability of the water storage anomaly (Figure 4) and the modeled water table depth anomaly (Figure 5) are correspondingly associated 

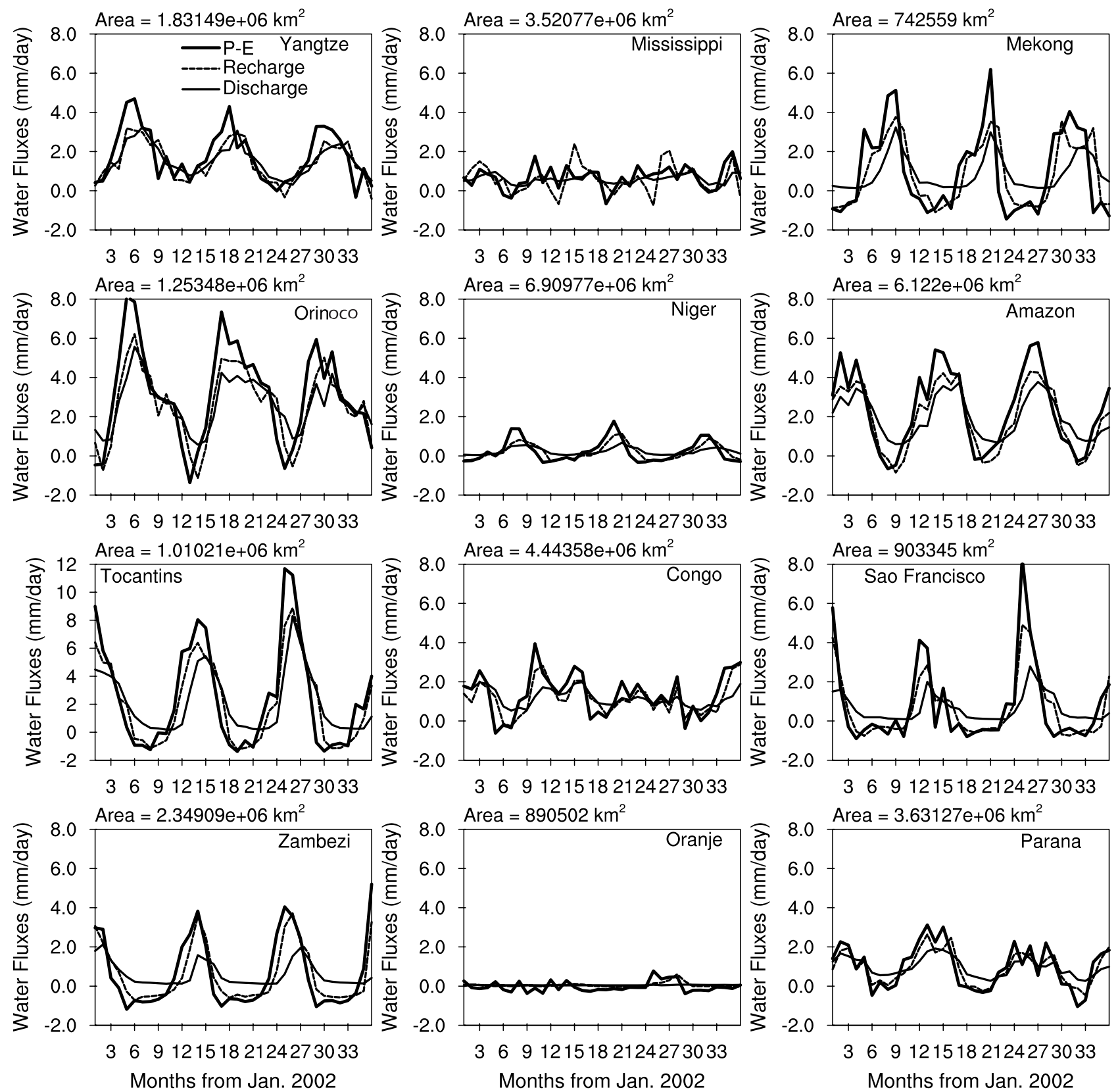

Figure 6. Modeled river-basin averaged $P-E$, groundwater recharge, groundwater discharge in various river basins.

with the variability of $P-E$ (Figure 6). For this reason, the modeled water table depth in this study can be called " $P-E$ driven water table depth" or "climate-driven water table depth."

\subsection{The Impacts of Including SIMGM in an LSM on} the Simulation of Soil Moisture and Evapotranspiration

[35] To investigate the impacts of groundwater dynamics on soil moisture and evapotranspiration, we conducted an additional experiment using gravitational free drainage (FD) as the model's lower boundary condition. The only difference between FD and SIMGM is the lower boundary of the modeled soil column. FD uses equation (4), while SIMGM uses equation (6).
[36] SIMGM produces a bottom soil layer that is up to $60 \%$ wetter (Figure 7a) than the FD experiment in all locations except for arid regions, in which the SIMGM water table is very deep. In turn, SIMGM simulates a surface soil layer that is up to $12 \%$ wetter than FD in arid regions (Figure $7 \mathrm{~b}$ ). The most pronounced impacts of the implementation of SIMGM on the surface soil moisture are observed in cold regions and arid-to-wet transition regions, the same regions as the "hot spots" identified by Koster et al. [2004], i.e., the regions where the coupling strength between the land surface and the atmosphere is great. Because of the limited surface energy in cold regions, the wetter soil has a negligible effect on $E$; the wetter soil in arid-to-wet transition regions has a larger impact on $E$, 


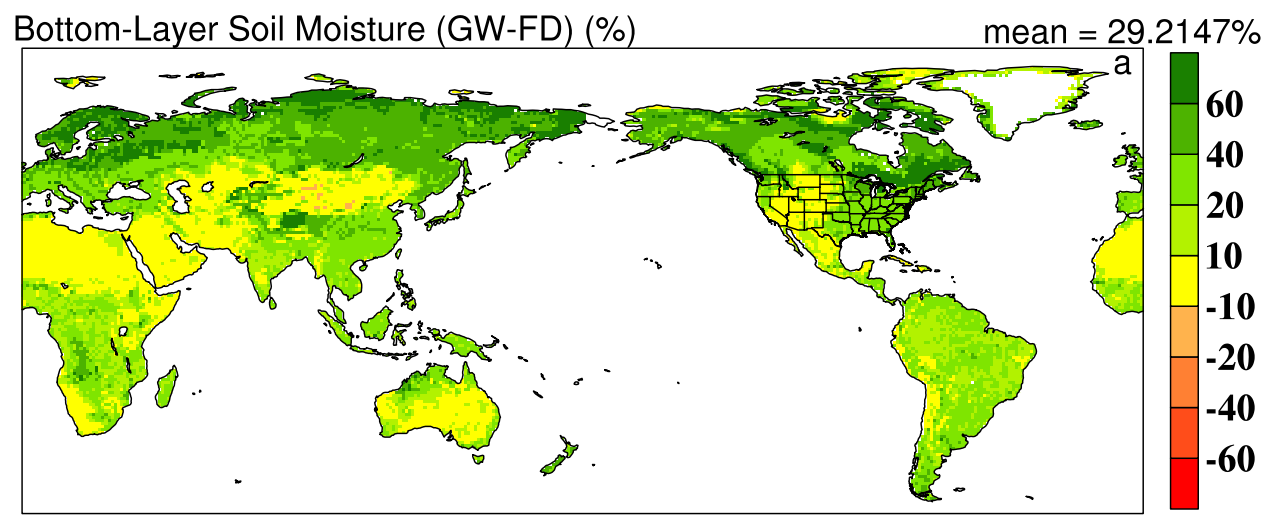

The 1st-Layer Soil Moisture (GW-FD) (\%) mean $=4.77309 \%$
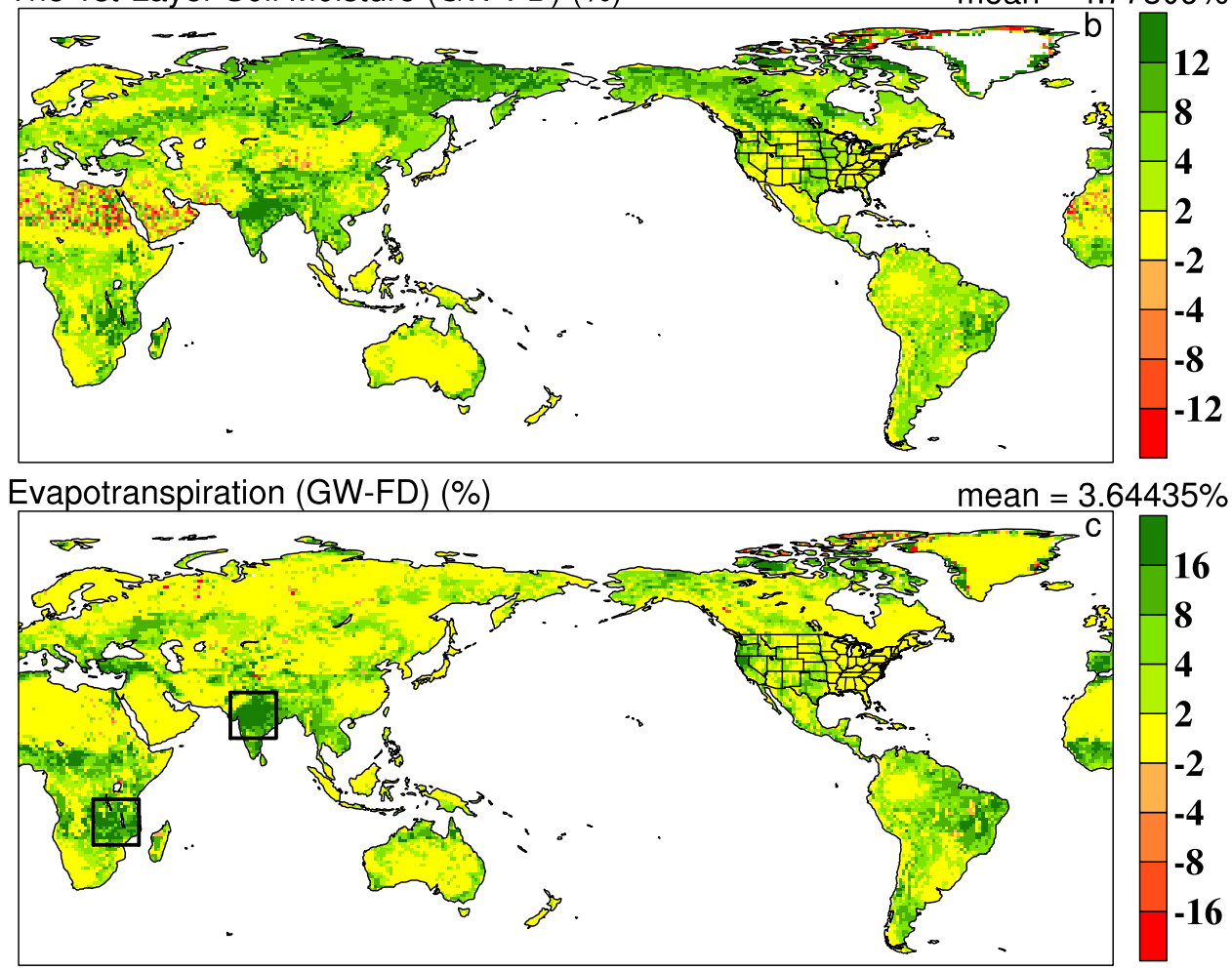

Figure 7. Differences between SIMGM and the model run in which a free drainage lower-boundary condition was used $(\mathrm{FD})(100 \times(\mathrm{SIMGM}-\mathrm{FD}) / \mathrm{FD})$. (a) Bottom-layer soil moisture, (b) surface-layer soil moisture, and (c) evapotranspiration.

producing up to $16 \%$ more $E$ than in the simulation using gravitational free drainage (Figure 7c).

[37] SIMGM produced remarkably wetter soil moisture profiles over most of the globe (Figure 8) than FD because of the greater leakage from the bottom layer soil in the FD run. Because the gravitational drainage is proportional to the bottom layer soil moisture, its impacts on the soil moisture profile in wet regions are much larger than those in arid regions.

[38] To investigate how different lower boundary conditions of the model's hydrology affect soil moisture and $E$, we analyzed soil-surface evaporation and transpiration separately in two of the most sensitive zones, India and Southeastern Africa; the area is shown in Figure 7c. SIMGM has almost negligible impacts on transpiration
(Figures 9a and 9e), even though SIMGM produced a much wetter deep soil layer (Figures 9c and 9g), because the plants are already transpiring at close to their maximum rate. However, SIMGM produced much larger soil-surface evaporation than FD (Figures 9b and 9f) in dry seasons because of the much wetter surface soil (Figures 9d and 9h). How groundwater dynamics affect $E$ may vary between models that have different functional relationships between the stomatal resistance and soil moisture.

\section{Summary}

[39] We developed a simple groundwater model (SIMGM) to represent groundwater dynamics in GCMs. SIMGM predicts groundwater storage and the water table depth by 

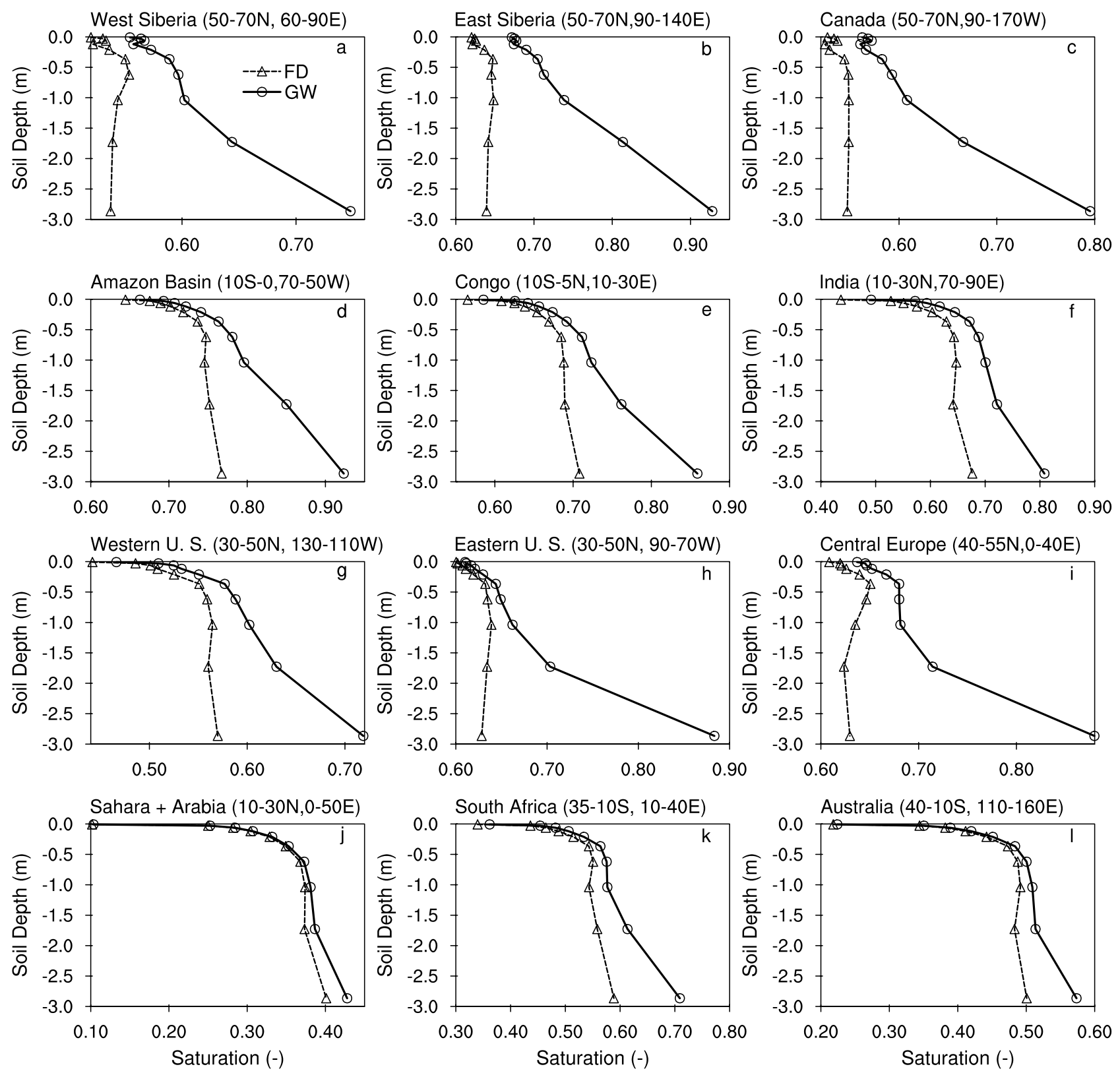

Figure 8. Same as Figure 3, but for annual-mean soil moisture profile.

representing recharge and discharge processes of the water storage in an unconfined aquifer, which is added as a single integration element below the soil column of the CLM.

[40] We evaluated SIMGM globally against the UNHGRDC runoff climatology. SIMGM equipped with the simple TOPMODEL-based runoff parameterization, in which both surface runoff and groundwater discharge are exponential functions of the water table depth, produced global runoff in good agreement with the GRDC runoff. The agreement between the modeled runoff and the GRDC runoff indicates that the mechanisms to generate runoff, i.e., the exponential dependence of runoff on water table depth, are applicable to most of the global continents.

[41] We compared the simulations of terrestrial water storage variations with GRACE estimates in river basins that are not affected by snow or frozen soil. The modeled total water storage anomaly (including groundwater and unsaturated soil water) compares fairly well with GRACE estimates in terms of interannual and interbasin variability. The anomaly of the groundwater storage explains most of the GRACE $\Delta S$ anomaly over a majority of river basins. Ideally, the modeled water table depth needs to be evaluated with in situ measurements over a wide range of spatial scales from local to regional. In practice, this is a difficult task because of dearth of high-quality in situ observations. Nevertheless, we compared the modeled water table depth variations to those of the converted water table depth from GRACE $\Delta S$ ( $\Delta S$ divided by the same specific yield as used in SIMGM). The modeled water table depth variations approximate those of GRACE converted. The interannual and interbasin variability of groundwater recharge, dis- 

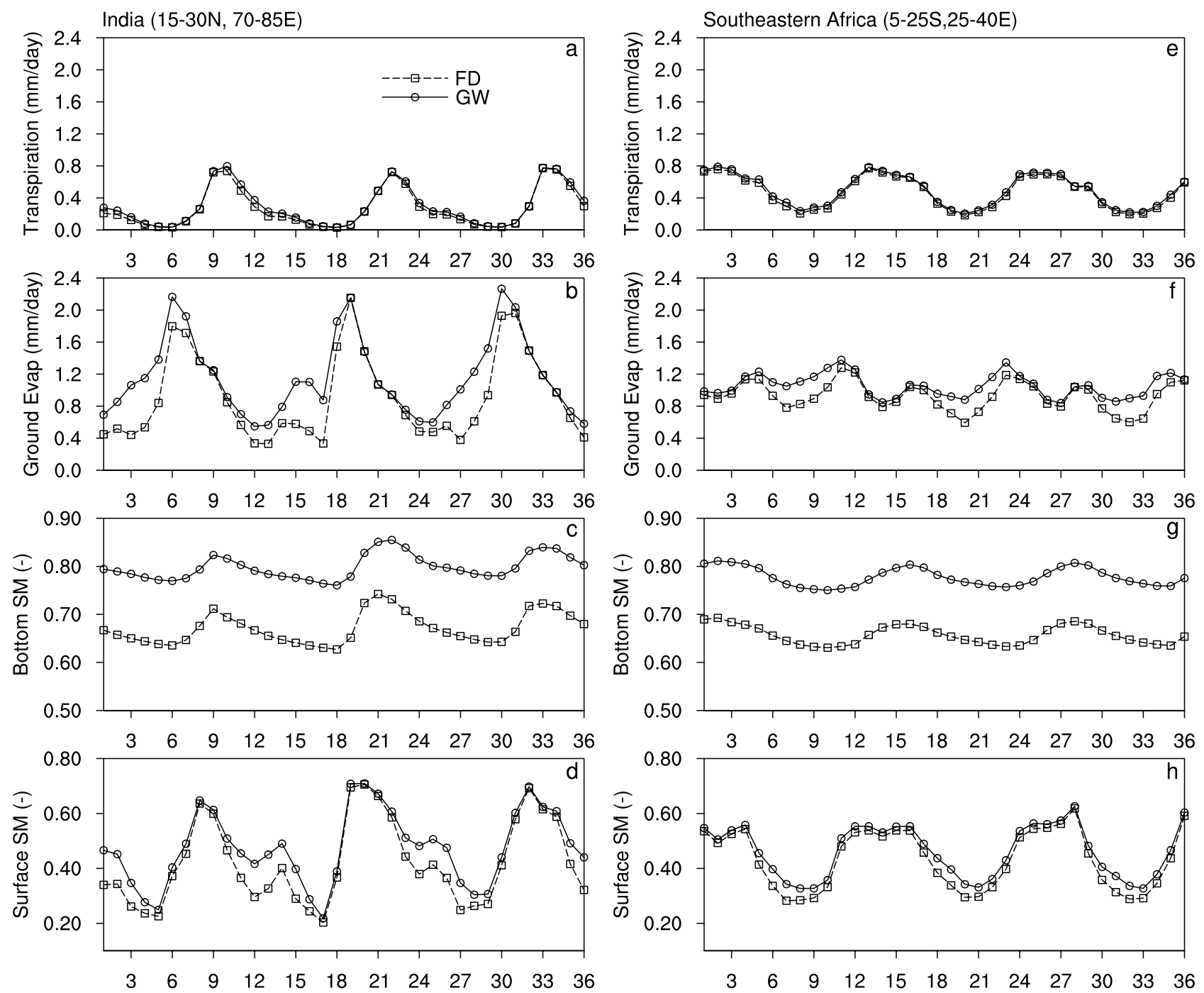

Figure 9. (a, e) Transpiration, (b, f) ground evaporation, (c, g) bottom-layer soil moisture, and (d, h) surface-layer soil moisture in two sensitive regions.

charge, and hence the groundwater storage and the water table depth are controlled by the variability of the difference between precipitation and evapotranspiration $(P-E)$.

[42] We also investigated the impacts of groundwater dynamics on soil moisture and evapotranspiration by comparing two experiments with different lower boundary conditions: groundwater recharge and gravitational free drainage. The former produced much wetter soil moisture profiles globally and from $4 \%$ to $16 \%$ more annual evapotranspiration than the latter, an effect that is most obvious in arid-to-wet transitional regions. Most of the enhanced evapotranspiration can be attributed to the increased evaporation from the soil surface because of the increased surface soil moisture, not to the transpiration from the deeper soil moisture through root-zone uptake.

[43] Acknowledgments. This work was funded by NASA grant NAG5-10209, NAG5-12577, and NOAA grant NA03OAR4310076. We thank Matthew Rodell for providing us with the GLDAS observationderived forcing data. We thank Jianli Chen and K.-W. Seo for providing us with the GRACE-derived data. We thank three anonymous reviewers whose comments helped improve the paper. The computing resources are provided by the Texas Advanced Computing Center (TACC).

\section{References}

Adam, J. C., E. A. Clark, D. P. Lettenmaier, and E. F. Wood (2006), Correction of global precipitation products for orographic effects, J. Clim., 19(1), 15-38.

Beven, K. J., and M. J. Kirkby (1979), A physically based, variable contributing model of basin hydrology, Hydrol. Sci. Bull., 24, 43-69.

Bonan, G. B., K. W. Oleson, M. Vertenstein, S. Levis, X. Zeng, Y. Dai, R. E. Dickinson, and Z.-L. Yang (2002), The land surface climatology of the Community Land Model coupled to the NCAR Community Climate Model, J. Clim., 15(22), 3123-3149.

Chen, X., and Q. Hu (2004), Groundwater influences on soil moisture and surface evaporation, J. Hydrol., 297(1-4), 285-300.

Chen, J., and P. Kumar (2001), Topographic influence on the seasonal and inter-annual variation of water and energy balance of basins in North America, J. Clim., 14, 1989-2014.

Chen, J. L., M. Rodell, C. R. Wilson, and J. S. Famiglietti (2005), Low degree spherical harmonic influences on Gravity Recovery and Climate Experiment (GRACE) water storage estimates, Geophys. Res. Lett., 32, L14405, doi:10.1029/2005GL022964.

Clapp, R. B., and G. M. Hornberger (1978), Empirical equations for some soil hydraulic properties, Water Resour. Res., 14, 601-604.

Dickinson, R. E., A. Henderson-Sellers, and P. J. Kennedy (1993), Biosphere-Atmosphere Transfer Scheme (BATS) version 1e as coupled to the 
NCAR Community Climate Model, NCAR Tech. Note, NCAR/ $T N-387+S T R$, Natl. Cent. for Atmos. Res., Boulder, Colo.

Dunne, T., and R. D. Black (1970), Partial area contributions to storm runoff in a small New England watershed, Water Resour. Res., 6(5), $1296-1311$.

Famiglietti, J. S., and E. F. Wood (1994), Multi-scale modeling of spatially variable water and energy balance processes, Water Resour. Res., 30(11), 3061-3078.

Fan, Y., G. Miguez-Macho, C. Weaver, R. Walko, and A. Robock (2007), Incorporating water table dynamics in climate modeling, Part I: Water table observations and the equilibrium water table, J. Geophys. Res., in press, doi:10.1029/2006JD008111.

Fekete, B. M., C. J. Vorosmarty, and W. Grabs (2000), Global composite runoff fields based on observed discharge and simulated water balance, Rep. 22, Global Runoff Data Cent., Koblenz, Germany. (Available at http://www.grdc.sr.unh.edu/html/paper/ReportUS.pdf).

Fetter, C. W. (1988), Applied Hydrogeology, 2nd ed., Merrill Publishing Company, Columbus, Ohio, 592 pp.

Gedney, N., and P. M. Cox (2003), The sensitivity of global climate model simulations to the representation of soil moisture heterogeneity, J. Hydrometeorol., 4, 1265-1675.

Gedney, N., P. M. Cox, R. A. Betts, O. Boucher, C. Huntingford, and P. A. Stott (2006), Detection of a direct carbon dioxide effect in continental river runoff records, Nature, Vol. 439, No. 7078, doi:10.1038/nature04504.

Gutowski, W. J., C. J. Vorosmarty, M. Person, et al. (2002), A coupled landatmosphere simulation program (CLASP): Calibration and validation, J. Geophys. Res., 107(D16), 4283, doi:10.1029/2001JD000392.

Koster, R. D., M. J. Suarez, A. Ducharne, M. Stieglitz, and P. Kumar (2000), A catchment-based approach to modeling land surface processes in a general circulation model: 1. Model structure, J. Geophys. Res., 105(D20), 24,809-24,822.

Koster, R. D., P. A. Dirmeyer, Z. C. Guo, et al. (2004), Regions of strong coupling between soil moisture and precipitation, Science, 305(5687), $1138-1140$.

Kumar, P. (2004), Layer averaged Richard's equation with lateral flow, $A d v$. Water Resour., 27(5), 522-532.

Liang, X., Z. Xie, and M. Huang (2003), A new parameterization for surface and groundwater interactions and its impact on water budgets with the variable infiltration capacity (VIC) land surface model, J. Geophys. Res., 108(D16), 8613, doi:10.1029/2002JD003090.

Maxwell, R. M., and N. L. Miller (2005), On the development of a coupled land surface and groundwater model, J. Hydrometeorol., 6, 233-247.

Niu, G.-Y., and Z.-L. Yang (2003), The Versatile Integrator of Surface and Atmosphere processes (VISA) Part II: Evaluation of three topographybased runoff schemes, Global Planet. Change, 38, 191-208.

Niu, G.-Y., and Z.-L. Yang (2006a), Effects of frozen soil on snowmelt runoff and soil water storage at a continental scale, J. Hydrometeorol., 7(5), 937-952.

Niu, G.-Y., and Z.-L. Yang (2006b), Assessing a land surface model's improvements with GRACE estimates, Geophys. Res. Lett., 33, L07401, doi:10.1029/2005GL025555.

Niu, G.-Y., Z.-L. Yang, R. E. Dickinson, and L. E. Gulden (2005), A simple TOPMODEL-based runoff parameterization (SIMTOP) for use in GCMs, J. Geophys. Res., 110, D21106, doi:10.1029/2005JD006111.

Oleson, K. W., et al. (2004), Technical description of the Community Land Model (CLM), NCAR Tech. Note, NCAR/TN-461+STR, Natl. Cent. For Atmos. Res., Boulder, Colo.
Pan, M., J. Sheffield, E. F. Wood, et al. (2003), Snow process modeling in the North American Land Data Assimilation System (NLDAS): 2. Evaluation of model simulated snow water equivalent, J. Geophys. Res., 108(D22), 8850, doi:10.1029/2003JD003994.

Quinn, P. F., J. Beven, and R. Lamb (1995), The $\ln (\mathrm{a} / \mathrm{tanb})$ index: How to calculate it and how to use it within the TOPMODEL framework, Hydrol. Processes, 9, 161-182.

Rodell, M., and J. S. Famiglietti (2001), An analysis of terrestrial water storage variations in Illinois with implications for the Gravity Recovery and Climate Experiment (GRACE), Water Resour. Res., 37(5), 13271339.

Rodell, M., J. S. Famiglietti, J. L. Chen, S. I. Seneviratne, P. Viterbo, S. Holl, and C. R. Wilson (2004a), Basin scale estimates of evapotranspiration using GRACE and other observations, Geophys. Res. Lett., 31, L20504, doi:10.1029/2004GL020873.

Rodell, M., P. R. Houser, U. Jambor, et al. (2004b), The global land data assimilation system, Bull. Am. Meteorol. Soc., 85(3), 381-394.

Sellers, P. J., Y. Mintz, Y. C. Sud, et al. (1986), A simple biosphere model (sib) for use within general-circulation models, J. Atmos. Sci., 43(6), $505-531$

Seo, K. W., and C. R. Wilson (2005), Simulated estimation of hydrological loads from GRACE, J. Geod., 78, 442-456.

Sivapalan, M., K. Beven, and E. F. Wood (1987), On hydrologic similarity: 2. A scaled model of storm runoff production, Water Resour. Res., 23, $2266-2278$

Stieglitz, M., D. Rind, J. Famiglietti, and C. Rosenzweig (1997), An efficient approach to modeling the topographic control of surface hydrology for regional and global modeling, J. Clim., 10, 118-137.

Tapley, B. D., S. Bettadpur, J. C. Ries, et al. (2004), GRACE measurements of mass variability in the Earth system, Science, 305(5683), 503-505.

Wahr, J., S. Swenson, V. Zlotnicki, et al. (2004), Time-variable gravity from GRACE: First results, Geophys. Res. Lett., 31, L11501, doi:10.1029/ 2004GL019779.

Wolock, D. M., and G. J. McCabe (2000), Differences in topographic characteristics computed from 100- and 1000-m resolution digital elevation model data, Hydrol. Processes, 14, 987-1002.

Yang, Z.-L., R. E. Dickinson, A. Henderson-Sellers, and A. J. Pitman (1995), Preliminary study of spin-up processes in landsurface models with the first stage data of Project for Intercomparison of Land Surface Parameterization Schemes Phase 1(a), J. Geophys. Res., 100(D8), $16,553-16,578$

Yeh, P. J. F., and E. A. B. Eltahir (2005), Representation of water table dynamics in a land surface scheme, Part I: Model development, J. Clim., 18(12), $1861-1880$.

York, J. P., M. Person, W. J. Gutowski, et al. (2002), Putting aquifers into atmospheric simulation models: An example from the Mill Creek Watershed, northeastern Kansas, Adv. Water Resour, 25(2), 221-238.

R. E. Dickinson, School of Earth and Atmospheric Sciences, Georgia Institute of Technology, 311 Ferst Drive Atlanta, Atlanta, GA 30332-0340, USA.

L. E. Gulden, G.-Y. Niu, H. Su, and Z.-L. Yang, Department of Geological Sciences, The John A. and Katherine G. Jackson School of Geosciences, The University of Texas at Austin, Austin, TX 78712-0254, USA. (niu@geo.utexas.edu; liang@mail.utexas.edu) 